\title{
Effect of Group Work on EFL Students' Attitudes and Learning in Higher Education
}

\author{
Hanan A. Taqi ${ }^{1} \&$ Nowreyah A. Al-Nouh ${ }^{1}$ \\ ${ }^{1}$ English Language Department, CBE, Ardhyia, Kuwait \\ Corresponding: Hanan Taqi, The English Department, College of basic Education, Kuwait. Tel: 965-9-608-8100. \\ E-mail: hanan.taqi@gmail.com
}

Received: February 16, 2014

Accepted: March 4, 2014 Online Published: May 14, 2014

doi:10.5539/jel.v3n2p52

URL: http://dx.doi.org/10.5539/jel.v3n2p52

\begin{abstract}
The use of group work in classroom activities is a method used for motivating learning and increasing the idea of pleasure through learning. The current study investigates the advantages of group work in exams in the English department, in the College of Basic Education. 40 students in two classes of "The Introduction of Phonetics and Phonology" participated in the study. They performed six tasks; two prior to group work, two done in group work (by one group only) and two after group work. The tasks were all practical, and they were based on phonetic transcription. One of the groups participated in group work while the other did not. This was done enable to compare the results. In addition to exam results, a five-open-questions questionnaire on the students' perception of group work was distributed to the participants. Throughout the application of the study, the instructor took notes of her observation of the formation of and participation in group work. It was found that the students who worked in groups did not improve. However, most students reported that they enjoyed the tasks and would like to work in a group more often. The method of forming a group also seemed to affect learning. It was found that social and academic variables of age and GPA affected the formation, engagement and results of group work.
\end{abstract}

Keywords: group work, cooperative, learning, assessment, perception

\section{Introduction}

According to Gomleksize (2007) cooperative learning is when students work together to achieve specific goals. A more comprehensive definition for cooperative learning is reported by Wichadee (2007) in her study of the effect of cooperative learning on students' English reading skills. Wichadee states that cooperative learning is a pedagogical approach that encourages student-student interaction by working in small groups to intensify their learning and reach their intended objective. Considerable research shows, that cooperative learning results in higher achievement and more positive relationships among students (Wichadee, 2007).

Group work also depends on the attitude of the students. Hashemi (2005) states that attitudes towards something is the extent to which students accept the subject and their opinion towards it while the Oxford Advanced Learner's Dictionary (2005) defined attitudes as 'the way someone thinks and feels about somebody or something' (p. 85).

Due to the large number of benefits and the amount of literature done, it was important to look at the effects of group work in different contexts. This study analyses the effectiveness of group work in the light of examination results, students' perception and instructor's observation. At first, a review of previous studies on the methods of group formation will be viewed. In addition, the effect of group work in general and on language skills in specific will be reviewed. Later, literature on the studies of student's perception of the effectiveness of group work will also be shown in detail. This would help in understanding the results of the current study.

After viewing the literature on the effect of group work, the methodology section will explore, in detail, the method of choosing the participants. Later, the researchers will elaborate on the three different methods of data collection, and the way the data was analyzed.

The results will be analyzed individually and in the light of social variables. From this analysis of results, a discussion section will link the findings with the literature reviewed, showing similarities and differences between the current study and previous ones. 
Finally, a short conclusion will be provided. It is hoped that this study will contribute to the understanding of the effectiveness of working in groups and classroom activities. It would be especially useful to practical programs in higher education in educational institutes worldwide.

\section{Literature Review}

Johnson (2005) describes cooperative learning as being a teaching strategy where students of different levels form small groups to work on activities that will eventually enhance their understanding of the subject. Every student is responsible of his/her learning and of helping other group members learn. Students work together to complete the assignment successfully. He believed that group work has many advantages.

\subsection{Advantages of Cooperative Learning}

\subsubsection{General Advantages}

A recent definition of cooperative learning is provided by Badache (2011) who defines group work as an instruction method where learners of different levels form small groups and work together towards a specific objective. Learners take the responsibility of their own learning and of those in the group so the success of one member is a success of all members.

Piaget (1932, in Webb, 2009: 3) argues that cognitive conflict leads to higher levels of reasoning and learning. When a student notices a conflict between her understanding and what she hears from other group members through interaction, this forces her to reconsider her concepts and restructure her ideas to conform to the group. Conflicting ideas lead to more questioning and negotiation which eventually results in learning. A more relevant theory is pointed out by Vygotsky $(1978$, in Webb, 2009) who adds that more learning occurs in a group when an expert adult helps a less expert one through conversation to carry out the job which the less expert wouldn't be able to do alone. Hull (1985, in Horder 2010) believes that adults learn best if they were put in groups. Working in groups allows learners to achieve higher order thinking skills and retain knowledge longer than working individually. In groups students discuss, argue, explain and negotiate meaning, they become more responsible for their learning and develop critical thinking skills (Johnson \& Johnson, 1986 in Smialek \& Boburka, 2006; Totten et al., 1991; Webb \& Palincsar, 1996).

Research findings suggest that group work technique helps students learn better and improves their achievement (Meteetham, 2001; Gomleksize, 2007; Al-Sheedi, 2009; Hendry et al., 2005). In Australia, Hendry et al. (2005) looked at the benefit of study groups on students' achievement. The opinions of 233 second year students at the University of Sydney were solicited via a questionnaire. They interviewed six students, three were in study groups and three were not. This was followed by a written summative test. Students reported that having their friends with them in the group was the most important factor in group formation. They also said that study groups helped them understand difficult concepts and corrected their misunderstandings. One disadvantage was wasting time socializing. It was concluded that group work helps students support each other while learning.

More recently, Brown (2008) argued that group work teaches learners to respect the learning pace of other learners in the group and improve their English language skills. It also created a stress-free environment where learners feel at ease. Added to that, shy students are more comfortable working in groups, they gain more confidence in their ability to learn; students benefit from sharing their backgrounds and complement one another's weakness (Payne \& Monk-Turner, 2006; Wichadee, 2007; Badache, 2011).

Highton (2006) argues that we can only learn by watching how others think and learn differently from us and this takes place through interaction. Johnson and Johnson (1989 in Smialek \& Boburka, 2006) did a meta-analysis of 375 studies done over a ninety-year period in which researchers tried to find out the effect of competitive individualistic versus cooperative learning on students' achievement. They concluded that cooperative learning resulted in better achievement than individualistic learning. Students gained higher-level reasoning, ability to solve problems and the ability to use what they learned from one situation to the other.

Previous literature has further documented differences in performance between those who performed at the group level and those who performed at the individual level. It has shown that group work helps students learn and remember knowledge better than individualistic learning (Cockrell et al., 2000; Johnson et al., 2000). Overall, research demonstrates that group work results in better achievement and more effective relationships among students (Gomleksize, 2007; Tuan \& Neomy, 2007; Wichadee, 2007; Li et al., 2010; Nihalani et al., 2010; Li \& Vandermensbrugghe, 2011; Arumugam et al., 2013). 


\subsubsection{Effect of Group Work on Language Learning}

Several studies have presented empirical support for the effect of group work on developing students' language skills (Holloway, 2004; Smialek \& Boburka, 2006; Tuan \& Neomy, 2007; Wichadee, 2007; Li \& Vandermenbrugghe, 2011; Arumugam et al., 2013; Larcombe et al., 2013). Li and Vandermensbrugghe (2011), for example, investigated the effect of group work on a group of 38 international research students. He looked at their thesis writing process in Australian university. They used classroom observation, a questionnaire and focus group discussion to get feedback from students. Results revealed that group work writing helped international students start their writing process, it motivated them to develop their writing skills, increased their self-confidence as writers and supported them through their writing.

On similar grounds, Larcombe et al. (2007) evaluated a program for a writing group at the University of Melbourne in Australia to specify the benefits of developing the identity of thesis writers through group cooperation. They concluded that the writing groups gave writers the chance to give and receive feedback on their work and to develop their identity as thesis writers.

Speaking received similar importance in Vietnam when Tuan and Neomy (2007) investigated group work pre-task planning and its effect on post planning individual oral presentation of 22 EFL second year college students at Hanoi who were enrolled in a four-year English program. Results showed group planning to focus on content rather than language and mixed proficiency grouping to benefit the most. Also in groups learners produced more ideas and learned more as more interaction took place. They concluded that group work aids students' in their oral presentation.

As for reading skills, Wichadee (2007), in Thailand, wanted to find out the effect of group work technique on improving students' reading skill. A group work technique was implemented on 40 first year students of the School of Communication and Arts at Bangkok University who were enrolled in an English course. A pre-test, post-test technique, a questionnaire, cooperative learning assessment, individual quiz and an interview were used. Wichadee reported that students benefited from group work in their reading comprehension, for example, their reading skill improved, their interaction increased, they felt at ease, learnt more, enjoyed their time and learnt how to work with one another.

Effect of group work on students' learning was further discussed by Al-Sheedi (2009), in Oman, who surveyed 240 Basic Education teachers' opinions about the effect of using group work to enhance students' learning of English. Ninety eight percent of the teachers believed that group work improved students' achievement. Also $98 \%$ agreed that students who work in groups learn more than those who work individually. They all agreed that group work is a useful technique to use in the classroom.

Group work technique has also proven to affect students' attitudes towards learning. For example, Ibnian (2012) wanted to find out the effect of group work on developing 64 Jordanian non-English major university students' attitudes towards learning English as a foreign language. The survey revealed that group work technique was useful in developing students' attitudes towards learning English by allowing them to express their ideas and opinions freely.

More evidence of students' learning in group work was reported by Meteetham (2001), in Thailand, who wanted to find out the development of students' grammar and competence as well as students' attitudes towards group work using a test, classroom observation, an interview and a journal. Results showed students receiving a high score in the test after working in groups and all students reported having more positive attitudes towards working in groups.

Finally, writing skill was investigated by Arumugam et al. (2013) who examined how group work affects university students' writing skill. To collect data they used a questionnaire, a pre and post-test and an interview. Results revealed significant development in scores between the pre and post tests. Students felt group work gave them the chance to learn and improve their English language skills. They felt that discussion in groups helped them to understand concepts better and they developed more positive attitudes as a result of working in groups.

\subsubsection{Effect of Group Work in Other Subjects}

Previously, the advantages of group work on language learning were shown. However, the effect of group work has also been investigated in different disciplines. For example, an earlier study by Hosterman (1992, in Smialek \& Boburka, 2006) investigated the effect of group work learning on students' knowledge, skills and attitudes in college music course. He used an experimental group where learning was in groups and a control group where they used traditional teaching. A final exam about their knowledge of music revealed that the experimental group scored higher than the control group on the listening section of the test. 
To investigate the effect of group work on students' critical thinking skills in Thailand Somapee (2002) used two groups, the experimental group used cooperative learning method and the control group used traditional learning method. Using a survey and a pre-post test, results showed that critical thinking skills of the experimental group outperformed those in the control group. Also students' attitudes towards group work were moderately positive.

To examine the effectiveness of group work as a technique compared with individual learning, Badache (2011) observed 36 first year students of English at Batna University in Algeria who were put into two groups, control and experimental taught by the same teacher. The same activities were given to both groups. The experimental did the activities in groups while the control did them individually. A questionnaire was designed and was used to solicit students' perceptions of working in groups and an observation sheet to record students' behavior in groups. The experimental group showed more cooperation, motivation and engagement. Students reported the development of their speaking skills as well as their critical skills.

\subsection{Group Work Formation}

To understand the reasons behind the effect of group work, whether good or bad, it is essential to understand how groups are formed. Friendship is one of the factors that can be put into consideration when forming group work. In such groups, students have excellent relationships. They respect each other, accept criticism from one another and listen to each other (Hendry et al., 2005). Friends work together; they work cooperatively instead of competitively. Groups can also be formed based on ability where clever students are grouped with weak ones. The point is to allow the weak students to watch and learn from high achievers, which will eventually improve their performance (Nihalani et al., 2010).

Furthermore, Hassanien (2007) proposes three types of group formation: randomly, where the teacher assigns students to groups, self-selection, where students choose their own group members, or a mixture of both. He further adds that a group of four or five is more convenient as students have the chance to participate equally in group activities. Other group formation criteria were proposed by Badache (2011) who suggested that groups can be formed alphabetically, by gender, or by birth. He even proposed to group students based on quite, shy and talkative students.

A more comprehensive description of group formation is presented by Ramirez (2005). He recommended interesting techniques that teachers can use to group students such as giving students numbers and then grouping them according to the numbers. Another way is to take a picture and cut it into pieces to form a puzzle. The number of pieces matches the number of students in a group. A student picks a piece and has to look for the rest of the pieces to form a group. Another technique asks the teacher to bring some pictures that form different categories and give them to students; then, ask students to look for other students who have the same picture category. However, these techniques would most probably depend on the age of the students.

\subsection{Perception of Group Work}

The effect of group work on students' learning would not be effective unless students work as a group. Thus, Chen \& Hird (2006) were interested to find out how 36 Chinese non-English major students behave in groups in an EFL classroom in Normal University. They recorded students during group discussions and interviewed them later. Results showed some students in the groups spoke more than others. This might be because they had eight members in one group. They also noticed students' speech in groups to be natural and spontaneous.

In a more recent study, Nihalani et al. (2010) aimed to find out how students collaborate within a group and its effect on group work success. They assigned 101 students randomly in groups of five to seven. To collect data, they recorded students' discussions during group work and used tests. Groups that performed better than others were found to work cooperatively and to agree on one right answer. However, groups where high performing students took control of the group had received low scores.

The studies on students' perceptions of group work point out that students enjoyed and benefited from working in groups (Greenop, 2007; Yazedjian \& Kolkhorst, 2007; Li et al., 2010). For instance, Li et al. (2010) examined students' perceptions of group work in Australia. Thirteen Chinese graduate and undergraduate students from two universities in Melbourne were interviewed. Students reported more engagement and discussion in groups, better understanding and the construction of new knowledge. They also had positive attitudes towards group tasks.

Furthermore, in Texas, Yazedjian and Kolkhorst (2007) examined students' perceptions of the effect of group work activities in developing active learning in a large lecture class. They applied small group activities on one hundred students studying a course in Human Development at the university. After the small-group activity, they distributed an activity assessment sheet to get feedback from students. Results showed students became more 
interested in the topic of the lecture, had the opportunity to meet with others and developed their social skills. Group discussions also deepened their understanding of topic content. Students became more active and more confident.

\subsection{Disadvantages of Group Work}

Although group work has plenty of advantages, there are some disadvantages as reported by research worldwide (Payne \& Monk-Turner, 2006; Hassanien, 2007). For example, when one group member dominates the group, group performance reflects the groups' member level instead of the whole group together (Nihalani, et al., 2010). Some students get praise for doing very little work while others do most of the work. Also sometimes students of one group fail to communicate with one another, or because of not having a teacher on their heads students may not take the work seriously. Some students in a group may work with their friends and leave others. Also, the teacher faces the difficulty of grading every group member. The time is another obstacle as many teachers complain that group work is time consuming (Mc Graw \& Tidwell, 2001). Another important disadvantage of group work is that some students work more than others. Different habits, where some students do not like to take orders from others is another obstacle. Some group members may refuse to work with others. Noise is one of the outstanding disadvantages that discourage many teachers from using group work. Some teachers also believe that once students are in groups, they lose control of the class. Also, in an EFL context, students might prefer using their native language, since it is easier for communication. And finally, in group work students may not get feedback on their errors.

In sum, group work as a technique has proven to be useful for all students. Research has shown that group work is a way for helping students socialize, get to know one another and learn about others' experiences. Students' language skills are developed as a result of working cooperatively. Students' attitudes towards learning English was found to be positive when teachers employ group work in their classrooms. Students' critical thinking skills are enhanced in group work. They learn how to argue, defend their position, question other students' ideas and convince others of their own. Finally, students' learning is improved and deepened. Group work was seen to generate a lot of discussion (Greenop, 2007; Li et al., 2010; Ibnian, 2012; Arumugam et al., 2013), lead to the construction of new knowledge (Tuan \& Neomy, 2007; Li et al., 2010), help students understand concepts better (Hendry et al., 2005; Greenop, 2007; Al-Sheedi, 2009; Li et al., 2010), learn more (Holloway, 2004; Smialek \& Boburka, 2006; Wichadee, 2007) and perform better on final exams (Meteetham, 2001; Smialek \& Boburka, 2006). Students in groups support and influence each others' learning (Hendry et al., 2005), clever students help weak students (Smialek \& Boburka, 2006; Tuan \& Neomy, 2007), weak students start to ask more questions and ask for help when they never do in a lecture (Smialek \& Boburka, 2006) and finally students become fully engaged in course content (Yazedjian \& Kolkhorst, 2007).

As seen from the above research much of the literature has been conducted in ESL contexts, very little research has been conducted in EFL contexts. As Clarke (2003) argued data taken from students in one culture cannot be over-generalized to a completely different culture. Thus, it is important to find out how students from a different culture engage with group work. For example, in an EFL context like ours, our education system values individual contribution over cooperative work, which might explain some students favoring individual work. Also in an EFL culture the teacher is usually seen at the center and students are waiting for the teacher to provide them with knowledge. In such a culture, students may chose not to exert an effort.

Although most of the previous research has shown the effect of group work on students' learning and attitudes, none of the previous studies have looked at how students collaborate to answer exam questions and how does that affect their performance on other exams and their attitudes. With these concerns in mind, the paper examines the following research questions:

1) What is the effect of group work on students' performance in the test?

2) How do students feel about working in groups?

3) Are there differences in students' achievement and attitude based on age, GPA, nationality and year of study?

\section{Methodology}

\subsection{The Participants}

The participants in this study were 40 EFL undergraduate students in the English department in the College of Basic Education in Kuwait (CBE hereafter). The students participating were all female (as there are no male students in the English major). The students were in their third and fourth year in college, very few where in college one semester more. The students were Kuwaitis and non-Kuwaitis. The reason this particular group of 
students was chosen was because of the course they were studying. The students were all in two "Phonetics and Phonology" classes, taught by the same instructor. This subject had plenty of practical exams and exercises, which could be done in a group or individually. The two groups would later be labelled: the first group (the one which would participate in group work), and the second group (which will always work individually).

\subsection{Instruments}

Data collection was combines three different parts. The first part was based on several phonetic-transcription exam results. In the beginning, two quizzes were given to the students to be answered individually to measure the student's competence. The first two exams contained one-syllable words for word-to-word transcription. Two other quizzes (three and four) were given later, where one class worked in groups to answer the questions and the other class solved it individually. The third exam was also a word-to-word transcription, but it contained two-syllable words. The fourth exam contained phrases to be transcribed by the students. Students decided to form their groups on their own, and the instructor allowed them. This is to promote more relaxation and comfort between the group members to work better together. Finally, a couple of quizzes (five and six) where given for the students to solve individually, by which the difference in their performance could be measured to know the usefulness of group work in improving the students' academic level. Exam five contained short phrases similar to the fourth exam. The sixth quiz contained transcription of sentences. The difficulty of the exams was raised gradually from one exam to the other due to the amount of practice the students had throughout the semester. Transcribing one-syllable words is slightly easier than two-syllable ones; and transcribing two-syllable words is slightly easier than transcribing phrases...etc. Hence difficulty depended on the phase the course was in at the time of the exam, and what the students are expected to know at by then. The difficulty of the exam was measured in a previous semester.

The second data source was an open-ended questionnaire containing two parts. In the beginning of the questionnaire, the participants were asked about their age, stage in CBE, nationality and GPA. These variables helped later to connect answers to social and academic status, and it also pinpointed certain differences and the reason these differences occurred. The second part of the questionnaire contained five open-ended questions about group work and assessment of group work. The questions were asked in two languages; namely Arabic and English. The questionnaire could be answered in any one of these two languages. This was done because the students' mother tongue is Arabic. It might be easier for them to express their feelings. A final question asked the students if there was anything they would like to add with respect to group work. This questionnaire was distributed at the end of the semester to insure that the students have a clear opinion on their reflection of group work. The final source of data was the observation of the instructor of the methods used to form groups, and methods used to answer the questions in the quizzes as a group. The instructor had a for categories on a sheet: 1 . Method of group formation, 2. Amount of work done in a group, 3. Socio and Academic affects, and 4. Reaction towards assessment. The instructor walked around the class from the minute the students started forming a group until they handed the paper in. Repetitive attitude and gestures where recorded to be able to count the frequency of certain phenomena.

\subsection{Data Collection and Analysis}

The grades of the six quizzes were all entered in SPSS to be analysed. Frequency and mean for every grade individually was obtained. The grades were also grouped in terms of pre-group-work and post-group-work. In addition, the grades were also analysed in light of the social and academic variables (independent variables). Significance was constantly obtained through a one-way, two-way, or multi ANOVA tests, T-test and descriptive analysis. The open-ended questions in the questionnaire were analysed carefully to find repetitive comments, which were counted. The frequency of repeated comments was calculated manually, then entered in SPSS for sifnificance. The results will be shown and examined in the light of the literature review.

\section{Results}

\subsection{The Exams}

The exams were all based on phonetic transcription. After the second week of teaching, the students were given a simple exam to measure the level of competency (one-syllable words). Although the first group received a higher average than the second group $(71.7 \%, 65 \%$ consecutively), the difference was not significant. A week later, another quiz was handed out, this exam contained two-syllable words. In analyzing the results obtained, it was found that significance occurred in the second exam, where a one-way ANOVA by students' group showed that $\mathrm{p}=0.020$ (where significance is measured at the value of $\mathrm{p} \leq 0.050$ ). This significance obviously occurred as the first group obtained better results in the quiz than the second group. The first group averaged $75.7 \%$ in the 
second exam as opposed to $67 \%$ obtained by the second group. It was established at this point that group one was more competent than group two, and this competence should be realized so as not to delude the researchers. The grade would be measured in the amount of advancement or deterioration only.

Table 1. Mean of exam grades for the two groups

\begin{tabular}{llllllll}
\hline students & & prexam1 & prexam2 & group1 & group2 & postgroup1 & postgroup2 \\
\hline group & Mean & 71.700 & 75.650 & 77.675 & 76.025 & 74.750 & 74.025 \\
work & $\mathrm{N}$ & 20 & 20 & 20 & 20 & 20 & 20 \\
& Std. Deviation & 12.187 & 12.712 & 8.088 & 7.734 & 13.123 & 12.410 \\
\multirow{2}{*}{ individual } & Mean & 64.900 & 66.975 & 66.875 & 67.100 & 69.300 & 67.625 \\
work & $\mathrm{N}$ & 20 & 20 & 20 & 20 & 20 & 20 \\
& Std. Deviation & 12.180 & 12.45780 & 13.138 & 14.230 & 13.062 & 13.611 \\
\multirow{2}{*}{ Total } & Mean & 68.300 & 71.312 & 72.275 & 71.562 & 72.025 & 70.825 \\
& $\mathrm{~N}$ & 40 & 40 & 40 & 40 & 40 & 40 \\
& Std. Deviation & 12.509 & 13.177 & 12.078 & 12.175 & 13.215 & 13.259 \\
\hline
\end{tabular}

Note. As can be seen in table 1, the first group performed better than the second group in all exams. Hence, the difference should be considered in the light of advancement.

When the two groups were given the third exam, the results showed $2 \%$ increase in the grades of the first group compared to their grades in the second exam, while the second group's average decreased by a mere $0.1 \%$. A one-way ANOVA by students' group showed significance in the performance of the two groups where $p \leq 0.01$. However, when the forth exam was given, the results were a little different. The average grade for the first group was $76 \%$, which shows a decrease by $1.6 \%$, while the average for the second group decreased by $0.3 \%$. At this point it appears that grades of the second group are steady and are not changing much; however, the grades of the first group show the exact opposite.

When the fifth exam was given, both groups worked individually again. The average grade of the first group deteriorated more (1.3\%), while an increase occurred in the average of the second group $(2.2 \%)$ changing the steadiness of the group. The final exam returned the steady status of the second group where they scored an average of $67.6 \%$, and the second group scored $74 \%$ showing a $0.7 \%$ decrease.

A further analysis of the results in the light of the social and academic variables showed that the effect of group work might change according to these variables. For example, when it comes to age, in the first group, the students' aged 24-29 received a significantly higher average than the two other groups $(\mathrm{p}=0.05)$. On the other hand, the youngest age group showed the highest grades when working individually. 
Table 2. Results of the exams by age groups

\begin{tabular}{|c|c|c|c|c|c|c|c|c|}
\hline students & age & & prexam1 & prexam2 & grp1 & grp2 & postgrp1 & postgrp2 \\
\hline \multirow[t]{4}{*}{ group work } & $18-23$ & Mean & 72.12 & 76.75 & 78.09 & 76.78 & 76.59 & 75.25 \\
\hline & & $\begin{array}{l}\text { Std. } \\
\text { Deviation }\end{array}$ & 12.478 & 12.922 & 7.603 & 7.009 & 12.576 & 11.907 \\
\hline & $24-29$ & Mean & 73.00 & 80.00 & 84.50 & 79.50 & 77.00 & 76.25 \\
\hline & & $\begin{array}{l}\text { Std. } \\
\text { Deviation }\end{array}$ & 9.899 & 7.071 & 7.778 & 13.435 & 15.556 & 16.617 \\
\hline \multirow{4}{*}{$\begin{array}{l}\text { individual } \\
\text { work }\end{array}$} & $18-23$ & Mean & 66.85 & 69.26 & 68.91 & 69.64 & 71.29 & 69.97 \\
\hline & & $\begin{array}{l}\text { Std. } \\
\text { Deviation }\end{array}$ & 11.397 & 11.561 & 12.260 & 12.077 & 11.997 & 11.916 \\
\hline & $24-29$ & Mean & 53.83 & 54.00 & 55.33 & 52.66 & 58.00 & 54.33 \\
\hline & & $\begin{array}{l}\text { Std. } \\
\text { Deviation }\end{array}$ & 12.413 & 10.392 & 14.223 & 19.731 & 15.620 & 17.672 \\
\hline
\end{tabular}

Note. As can be seen in Table 2, age affected learning in groups and individually.

As for the years in CBE, it appears that $4^{\text {th }}$ year students had significantly the lowest scores in the individual exams ( $\mathrm{p} \leq 0.01$, where significance is measured at $\mathrm{p} \leq 0.05$ ). The most significant change was found in the analysis of the data by GPA, where the level of competence for the students with low GPA have significantly deteriorated in comparison to their grades when working in groups $(\mathrm{p}=0.29)$. The other two GPA groups showed a much more stable competence level. The group with a GPA of 300-4.00 showed a slight increase from group work to individual work at the end of the semester. Nationality did not reflect any significance in terms of the decrease or increase of grades. This being said, this study has established that the findings could be applied in any other country.

It appears from comparing the results of the exams prior and post to group work that the grades did not significantly increase; hence, it seems that group work did not boost the learning ability of the students. However, a slight increase in the grades of the students who did not participate in group work was seen.

\subsection{The Questionnaire}

The questionnaire was handed out at the end of the semester to allow students to reflect on their own experience. It was especially important to view the ideas of the students who had the chance to work in groups as opposed to the students who always worked individually.

The questionnaire consisted of four open questions:

a. How useful do you think it is to work in a group?

b. How do you work in a group?

c. Do you prefer group work? Why?

d. How do you feel about the assessment of group work?

And finally, they were asked if they had any other comments.

Out of the forty questionnaires, only seven students did not believe that group work is useful. It was found that six out of the seven students who do not believe that group work is useful worked in a group (belonged to the first group). The reason they did not feel the usefulness of the task was their belief that "group work" is never done fairly, and that it is mostly a one-man job. What makes the other thirty-three students feel that group work is useful? Many reasons were given, yet the most common were the following:

a. It saves time especially with long tasks.

b. It develops communicative skills.

c. It improves grades 


\section{d. It helps practice cooperation.}

When asked about their method of group work, most students answered similarly. They believed that cooperation should be encouraged throughout the tasks. Students commented that they would write an answer and ask the other members about their opinion, or what did they write? While half the participants stated that they would show their opinion without hesitation, the other half believed that they should listen well to all comments to be able to understand and decide whether their answers were correct or incorrect. $70 \%$ of the participants believed that the first step to take in consideration when starting group work was choosing the members. They believed that working with friends and people you feel comfortable working with is the key to a successful group work. In addition, many felt that if the group was friendly, they would not hesitate to give their opinions openly; yet, if they did not feel comfortable, they would prefer to listen only. Only $30 \%$ of the participants preferred to do the task on their own. Once they were done, they would show their answers to their group. In this case, they would miss the discussion within the group.

While $22.5 \%$ of the students did not prefer group work, $77.5 \%$ seemed to enjoy it more than working individually. The same students who did not like to work in a group also believed that group work assessment was not fair; the majority of which (55.5\%) had GPA above 3.00. The common reasons these students gave for preferring to work alone was the lack of cooperation among some group members, and that they felt they were working alone while the credit went to the entire group. In addition to these two common reasons, some students felt more comfortable and focused while working on their own. Moreover, a couple of students felt that group work is confusing, and found that the weaker students sometimes interfered to ruin the job of the other students by either insisting on wrong answers or spreading constant doubt. Unfair assessment was the main cause these students did not like group work. They felt that while some worked more than others, the group receives the same grade.

All the students who preferred group work felt that it is more motivating. $54.8 \%$ felt that the work they presented was more creative. Some students added that they gave attention to the work more than they usually would as they felt an obligation to help the other group members. Consequently, most students made new friendships and enjoyed the class more.

The assessment of group work seemed fair to the $77.5 \%$ participants as it represented the work of the group. However, some students hoped that the instructor could insist on full cooperation of the entire group members, as some members seemed very quite. Additionally, three students proposed that at the end of the task, each student would hand in her own paper which might contain slight differences between the papers of the rest of the group.

In the additional comments slot, many students hoped that every class would include a task or two of group work. They felt that it gave them more enjoyment.

\subsection{Observation}

The instructor tended to observe the students while forming the groups and while they were solving the tasks having the four categories listed above at hand. Many important issues were noticed and written for frequency calculation. Only frequent attitudes were reviewed in this paper. First, when the students tended to form the group, most of them choose to work with close friends. Hence, some groups consisted of only two students. Some students would choose to work with more competent students. Other students did not seem to mind, they formed a minority. Very few seemed reluctant to join a group; it seemed that they preferred to work alone.

The students who work with competent students were those who had high GPA. These groups were the most interactive and highly enthusiastic. When handing in their tasks to the instructor, they would insist that their paper was instantly marked.

It was also noticed that nationality formed a barrier in group work. In spite of the fact that most students divided themselves based on nationality (while some on GPA), some groups contained mixed nationalities. The mother tongue of the complete class is Arabic and all the members could speak English. Nonetheless, within the multi-national group, one nationality would seem more in control of the group. The instructor constantly passed by the group asking the members for more cooperation. The students with higher GPA also tried to take over control of the group, yet this attempt was not successful all the time.

Unfortunately, some students were very passive, and hardly participated even though the instructor kept asking them to participate and take part in the discussions. This made the job of the instructor difficult in terms of assessment. Although the group was assessed for the task as one, the participation grades were deducted for the less participating members. 


\section{Discussion}

The study was conduct with different methods of data collection. Each tool helped provide information on the advantages and disadvantages of group work in an undergraduate course provided for students who are English teachers to be. It was found from the exams that the students who worked in groups gained higher grades while working in groups, yet after working individually again, the grades decreased to return to a mean close to the mean of the pre-group-work exam. This finding disagrees with many studies presented on the learning advantages of group work. An early example was presented by Piaget's 1932 masterpiece, were he found that through cognitive conflict students changed their own concepts and adopted new ones presented in their groups. A more recent study was conducted by Cockrell et al. (2000) and Johnson et al. (2000), which showed that the results of group work were better than that of individual work. They stated that group work helped students remember information better than the students who worked individually. Many other studies supported this idea (Gomleksize, 2007; Tuan \& Neomy, 2007; Wichadee, 2007; Li et al., 2010; Nihalani et al., 2010; Li \& Vandermensbrugghe, 2011 among others).

However, when the results were investigated in light of the social and academic affects, it was found that age, GPA and years in CBE affected the students' results when working in groups or individually. It was found that when students with high GPA worked in a group together, they improved and reflected better learning. Vygotsky (1978, in Webb, 2009) stated that more learning occurs in a group where an expert adult helps the less expert one to do a job the less expert would not normally be able to do alone. The less expert student seems to have a choice at this point: either to carry out the job as instructed without completely understanding it, or to ask and discuss in order to understand. Through observation, it was found that most students try not to argue with the "expert student" (those with high GPA). Hence, the groups that contained one student with a GPA of 3.00 and above and other members with 2.00 and less did not discuss the questions properly as a group; instead, they relied on the knowledge of the "expert student". Later, the weaker students found that their answers were correct, but they did not have enough confidence to argue with the expert student.

Students on the second-group-quiz preformed better as they have raised the level of confidence in their knowledge. In addition, they showed better ability to argue, discuss and negotiate. This agrees with Mutch, 1998 and Gillies, 2000 who found that group work built a positive learning environment where students become actively involved in learning.

A main finding in this study, which might reflect the effect of culture on learning, is the effect of age. Age has shown to contribute to group work learning significantly. Students aged 24-29 worked best in groups while the youngest age group showed higher grades when working individually. As for years in college, it was found that students who have been in CBE for more than 4 years did not do well on individual exams, but preformed well in group work. This finding agrees with Clarke (2003) who believed that culture had a significant effect on learning and learning outcome.

As for the students' perception and the instructors' observation, the researchers found that the results were not much different than some recent literature. As many studies agreed (Greenop, 2007; Yazedjian \& Kolkhorst, 2007; Li et al., 2010 among many others), the effect of group work on students' went beyond learning the material at hand. The students in this study reflected enjoyment during group work. Through the open-questions questionnaire, the majority expressed their delight in working in a group and socializing with other students. Many felt that they have benefited by improved communicative skills. The findings of this study coincided with Greenop (2007) who reported that students enjoyed their ability to talk and hear other people's opinion. Moreover, some reported that they understood the topics better when working in a group. Very few students preferred the traditional methods of examination.

The development of the social skills was reported by the students in the questionnaire and was also noticed through observation. In the second-group-quiz, the instructor noticed that the students had developed more courage to discuss their points of view, regardless of their GPA. The students interacted more in the second group-quiz, which reflected more confidence and understanding of the material. Many students in this study reported that group work helped them answer the questions in less time than they would normally need when working individually. Mc Graw and Tidwell (2001) stated that many teachers complain that group work is time consuming. This study found opposite results.

Many studies showed that language skills improved during group work (Hoserman, 1992; Wichadee, 2007; Sompee, 2002 among others). The instructor also found through observation that when working in groups, students became more accustomed to using scientific terminology and used the names of the phonetic symbols instead of referring to their sounds only as they did in the beginning of the semester. 
Group formation was one of the most important parts of observation. Most literature conducted on group work looked at the methods of group formation. Hassanien (2007) stated that there are three types of group formation; random teacher group assigning, students selection or a mixture of both. In the current study the instructor gave the students the opportunity to form their own groups. Friendship was the most common criteria of group formation for the students. As Hendry et al. (2005) reported, friendship helped the groups work better as the group members have a good relationship with each other, were not afraid of criticizing and discussing, and had great respect for all members. When friendship was not an option, the second choice seemed to be GPA. Students with high GPA grouped themselves together. These groups kept a high standard through out the exams, and showed slight improvement at the end of the semester.

Nationality did not affect the results of the exams; however, it affected the process of group formation. As culture has been shown to affect learning, it is possibly the reason behind the separation of nationalities when grouping.

Although with group work students were more motivated to work, and accomplished a high level of communicative skills, it does have some disadvantages found in this investigation and in previous investigations.

The instructor found that in a few groups showed dominance by one group member. The grades obtained from the group reflected the level of the dominant group member not the entire group. Nihalani et al. (2010) reported that the dominance of one group member caused a set-back for the group and the results reflected the level of one group member, the dominant one.

Furthermore, in terms of assessment, it would be unfair to give the entire group a grade for the work of one member. Consequently, if the group did well and was a one-member based group, every other member will get praise for the job of the one-member. Therefore, it is of high importance that the instructor does not leave the students alone while working in groups, as constant observation would lessen the one-member work and increase highly communication and cooperation. In addition, constant observation would limit the use of the native language in an EFL context as was the case in the current study.

\section{Conclusion}

The use of group work in classroom activities has shown its usefulness in many fields of education. Many studies reported better learning and improved level of understanding, while others found group work to be useful in teaching communicative skills and build better debate characteristics.

This study found that group work improved learning with certain social and academic groups only. These groups were between ages 24-29 and highest GPAs. Yet, most students felt that their communicative skills improved. They reported that they believed they became better listeners and open to criticism. Learning new social skills was also found to be a major advantage in group work. Students found that at the end of the semester, they were able to form new friendships and enjoyed the company of other students.

The most evident effect of group work reported by the instructor through observation and by the students through the open-ended questionnaire was increase of motivation. The students who worked in groups came early and were very enthusiastic towards working in a group. The competitive feature made working more exciting and students reported that they enjoyed taking group exams as opposed to individual exams.

The main disadvantage of group work, however, is the dominance of one member in the group. This dominance was either affected by GPA or by nationality. It was found that when groups were multi-national, one nationality would be dominant and the rest of the members would hesitate to interfere. It was also observed that low GPA students would prefer to listen most of the time. However, with a little encouragement from the other group members, they would start to participate more.

This study is considered useful for teachers in higher education. Without group work, the students may feel bored. Mixing individual work with group work raises interest and enjoyment. The researchers, thus, recommend that instructors in higher education try to find a slot or two for group work in the syllabus. They will notice a difference in the students' learning attitude.

In this study, it was found that the advantages of group work was more than the disadvantages if a few steps were taken when forming and working in a group. For example, the groups can be formed earlier in the beginning of the semester to give students a chance to familiarize themselves with their peers and become more comfortable to engage in any discussion. Moreover, the instructor should constantly view the work of the group members to encourage cooperation and stop the "one-member job" phenomenon. It would also seem useful to 
talk to students about the benefits of group work and the essential points to consider when forming and working in a group.

\section{References}

Al-Sheedi, M. (2009). Teachers' beliefs about using group work in Basic Education. In S. Borg (Ed.), Researching English Language and Teacher Development in Oman. Ministry of Education, Sultanate of Oman.

Arumugam, N., Rafik-Galea, S., Mello, G. D., \& Dass, L. C. (2013). Cultural influences on group learning in an ESL classroom. Review of European Studies, 5(2), 81-89. http://dx.doi.org/10.5539/res.v5n2p81v

Badache, L. (2011). The Benefits of Group Work. The Social Science and Human Journal. Retrieved from http:/repository.yu.edu.jo/handle/123456789/449014

Brown, F. A. (2008). Collaborative learning in the EAP classroom: Students' perceptions. English for specific purposes world. Online Journal for Teachers Issue, 1(17), 7.

Chen, R., \& Hird, B. (2006). Group work in the EFL classroom in China: A closer look. Regional Language Centre Journal, 37(1), 91-103.

Clarke, D. (2003). International comparative studies in mathematics education. In A. J. Bishop, M. A. Clements, C. Keitel, J. Kilpatrick, \& F. K. S. Leung (Eds.), Second International Handbook of Mathematics Education. Dordrecht: Kluwer Academic Publishers. http://dx.doi.org/10.1007/978-94-010-0273-8_6

Cockrell, K. S., Hughes Caplow, J. A., \& Donaldson, J. F. (2000). A context for learning: Collaborative groups in problem based learning environment. Review of Higher Education, 23(4), 347-363. http://dx.doi.org/10.1353/rhe.2000.0008

Gillies, R. M. (2000). The maintenance of co-operative and helping behaviours in co-operative groups. British Journal of Educational Psychology, 70, 97-112. http://dx.doi.org/10.1348/000709900157994

Gomleksize, M. N. (2007). Effectiveness of cooperative learning (jigsaw II) method in teaching English as a foreign language to engineering students (case of Firat University, Turkey). European Journal of Engineering Education, 32(5), 613-625. http://dx.doi.org/10.1080/03043790701433343

Greenop, K. (2007). Students' perceptions of efficacy and preference for two lecture formats. South African Journal of Psychology, 37(2), 361-367. http://dx.doi.org/10.1177/008124630703700212

Hashemi, H. (2005). The effectiveness of a proposed program for teaching Arab language in achievement and attitudes of non-native speakers in Oman (Unpublished Ph.D. Thesis). Cairo University.

Hassanien, A. (2007). A qualitative student evaluation of group learning in higher education. Higher Education in Europe, 32(2), 135-150.

Hendry, G. D., \& Davy, H. P. (2005). Independent student study groups. Blackwell Publishing Ltd. Medical Education, 39, 672-679. http://dx.doi.org/10.1111/j.1365-2929.2005.02199.x

Highton, M. (2006). Vulnerable learning: Thinking Theologically about Higher Education. Cambridge: Grove.

Holloway, M. S. (2004). The use of cooperative action learning to increase music appreciation students' listening skills. College Music Symposium, 44, 83-93.

Horder, J. (2010). Encouraging vulnerable learning: Student responses to group work experience. JATE, 1, 60-77. http://dx.doi.org/10.1558/jate.v7i1.60

Hosterman, G. L. (1992). Cooperative learning and traditional lecture demonstration in an undergraduate music appreciation course. Dissertation Abstracts International, 53(5), 1440.

Hull, J. (1985). What prevents Christian adults from learning? London: SCM Press.

Ibnian, S. (2012). Group work and attitudes of non-English major students towards learning EFL. International Journal of Humanities and Social Science, 2(4), Special Issue.

Johnson, R. T., \& Johnson, D. W. (1986). Action research: Cooperative learning in the science classroom. Science and Children, 24, 31-32.

Johnson, D. W., \& Johnson, R. (1989). Cooperation and competition: Theory and research. Edina, MN: Interaction Book Company. 
Johnson, D. W., \& Johnson, R. (2000). Joining together: Group theory and group skills (7th ed.). Needham Heights: Pearson Education.

Johnson, D. (2005). Cooperative learning: Increasing college faculty instructional productivity. Retrieved December 11, 2013, from http://www.ntlf.com/htm/lib/bib/92-2dig.htm

Larcombe, W., McCosker, A., \& O'Loughlin, K. (2007). Supporting education PhD and DEd students to become confident academic writers: An evaluation of thesis writers' circles. Journal of University Teaching and Learning Practice, 4(1), 54-63.

Li, L. Y., \& Vandermensbrugghe, J. (2011). Supporting the thesis writing process of international research students through an on going writing group. Innovations in Education and Teaching International, 48(2), 195-205.

Li, D., Remedios, L., \& Clarke, D. (2010). Chinese students' perception of out-of-class group work in Australia. The Australian Educational Researcher, 37(3), 95-112. http://dx.doi.org/10.1007/BF03216932

Meteetham, P. (2001). Case study of cooperative learning by using jigsaw technique with second-year English major students at Naresuan University (M.A. Thesis, Mahidol Univeristy).

Nihalani, P., Wilson, H., Thomas, G., \& Robinson, D. (2010). What determines high-and low-performing groups? The superstar effect. Journal of Advanced Academics, 21(3), 500-529. http://dx.doi.org/10.1177/1932202X1002100306

Piaget, J. (1932). The language and thought of the child (2nd ed.). London: Routledge and Kegan Paul.

Payne, B. K., \& Monk-Turner, E. (2006). Students' perceptions of group projects: The role of race, age and slacking. College Student Journal, 40(1), 132-139.

Ramirez, M. S. (2005). Grouping techniques in an EFL classroom. Revista Electronica "Actualidades Investigativas en Educacion", 5(1), 1-14.

Smialek, T., \& Boburka, P. (2006). The effect of cooperative listening exercises on the critical listening skills of college music-appreciation students. Journal of Research in Music Education, 54(1), 57-72. http://dx.doi.org/10.1177/002242940605400105

Somapee, S. (2002). The effectiveness of using cooperativeness of using cooperative learning to enhance students' critical thinking skills in business English I at Chiangrai commercial school in Chiangrai (M.A. Thesis, Payap University).

Totten, S., Silk, T., Digby, A., \& Russ, P. (1991). Cooperative learning: A guide to research. New York: Garland.

Tuan, T. A., \& Neomy, S. (2007). Investigating group planning in preparation for oral presentations in an EFL class in Vietnam. Regional Language Centre Journal, 38(1), 104-124.

Vygotsky, L. (1978). Interaction between learning and development. Mind in Society. Cambridge: MA: Harvard University Press.

Webb, N. M. (2009). The teacher's role in promoting collaborative dialogue in the classroom. British Journal of Educational Psychology, 79, 1-28. http://dx.doi.org/10.1348/000709908X380772

Webb, N. M., \& Palincsar, A. S. (1996). Group processes in the classroom. In D. Berliner, \& R. Calfee (Eds.), Handbook of educational psychology. New York, NY: Macmillan.

Wichadee, S. (2007). The effect of cooperative learning on English reading skills and attitudes of the first-year students at Bangkok University. Presented at the conference of languages for specific purposes in Higher Education - Searching for Common Solutions organized by Brno University of Technology, Czech Republic. November, 29-30-2007.

Yazedjian, A., \& Kolkhorst, B. (2007). Implementing small-group activities in large lecture classes. College Teaching, 55(4), 164-169. http://dx.doi.org/10.3200/CTCH.55.4.164-169 


\section{Appendix A:}

\section{The Questionnaire}

Age group: $\square 18-23 \quad \square 24-29 \quad \square 30-35 \quad \square 36+$

Years in CBE: $\square 2^{\text {nd }}$ year $\square 3^{\text {rd }}$ year $\square 4^{\text {th }}$ year $\square$ more (please specify)........

GPA: $\square 1.00-1.99 \quad \square 2.00-2.99 \quad \square 3.00-4.00$

Nationality $\square$ Kuwaiti $\quad \square$ non-Kuwaiti (please specify)

1. How useful do you think it is to work in a group?كا فائدة العمل الجماعي في نظرك؟

كيف تعمل مع المجموعة؟ How do you work in a group?

هل تفضل العمل الجماعي؟ لماذا؟ Do you prefer group work? Why?

هل تعتقد أن التقيبم للعمل الجماعي مناسب؟ How do you feel about the assessment of group work?

2. Any additional information in relation to group work? هل هنالك شيء تود أن تضيفه منعلق بالعمل الجماعي؟

\section{Copyrights}

Copyright for this article is retained by the author(s), with first publication rights granted to the journal.

This is an open-access article distributed under the terms and conditions of the Creative Commons Attribution license (http://creativecommons.org/licenses/by/3.0/). 